\title{
Consider the wrist: a retrospective study on pediatric connective tissue disease with MRI
}

\author{
Charlotte M. Nusman ${ }^{1,2}$ - J. Merlijn van den Berg ${ }^{2}\left(\mathbb{0} \cdot\right.$ Amara Nassar-Sheikh Rashid $^{2}\left(\mathbb{0} \cdot\right.$ Katerina Ntailiani $^{3}$.

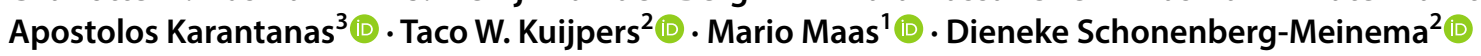

Received: 26 April 2019 / Accepted: 17 June 2019 / Published online: 20 June 2019

(c) The Author(s) 2019

\begin{abstract}
The aim of this study is to describe the clinical characteristics and MRI findings of the wrist in a cohort of children suffering from connective tissue disease with musculoskeletal involvement. Ten patients with pediatric connective tissue disease [median age 14.7 years (IQR 12.7-16.6 years), 70\% female] were identified from a large MRI database. Clinical findings during the disease course were retrospectively obtained from patient charts and findings at the time of MRI were prospectively registered in the MRI database. MRI wrist datasets were evaluated by three readers in consensus for synovitis, tenosynovitis, bone marrow changes, bone erosions and myositis. Patients suffered from connective tissue disease with clinical overlap of subtypes systemic lupus erythematosus, Sjögren syndrome and dermatomyositis. Median onset of disease was at 12.3 years (IQR 7.8-14.8 years). Clinical arthritis activity was scored low (median visual analogue scale physician 19, IQR 7-31). Notwithstanding, extensive inflammatory abnormalities such as synovitis and tenosynovitis were found in the wrist of $7 / 10$ patients. Osteochondral involvement was detected in 3/10 patients. In a small cohort of children with connective tissue disease and musculoskeletal symptoms, severe inflammatory abnormalities of the involved wrist were present in the MRI, while clinical disease scores suggested mild disease activity. Therefore, clinicians should consider the wrist as vulnerable for joint damage and can add MRI as a helpful tool in the management of patients with pediatric connective tissue disease and musculoskeletal involvement.
\end{abstract}

Keywords Connective tissue disease $\cdot$ Magnetic resonance imaging $\cdot$ Wrist $\cdot$ Autoimmune $\cdot$ Synovitis

Charlotte M. Nusman

c.m.nusman@amc.uva.nl

J. Merlijn van den Berg

j.m.vandenberg@amc.uva.nl

Amara Nassar-Sheikh Rashid

a.nassar@amc.uva.nl

Katerina Ntailiani

kdailiani@gmail.com

Apostolos Karantanas

karantanas@med.uoc.gr

Taco W. Kuijpers

t.w.kuijpers@amc.uva.nl

Mario Maas

m.maas@amc.uva.nl
Dieneke Schonenberg-Meinema

d.schonenberg@amc.uva.nl

1 Department of Radiology, Amsterdam University Medical Center, Meibergdreef 9, 1105 AZ Amsterdam, The Netherlands

2 Department of Pediatric Immunology, Rheumatology and Infectious Disease, Emma Children's Hospital, Amsterdam University Medical Center, Meibergdreef 9, 1105 AZ Amsterdam, The Netherlands

3 Department of Medical Imaging, Heraklion University Hospital Crete, 71110 Voutes, Greece 


\section{Introduction}

Connective tissue disease with potential musculoskeletal involvement in children comprises several disorders, such as systemic lupus erythematosus (SLE), mixed connective tissue disease (MCTD), systemic sclerosis (SSc) and juvenile polymyositis/dermatomyositis (PM/DM). Besides the variety of musculoskeletal symptoms, the above-mentioned disorders can manifest in many other organ systems [1]. For SLE, the recent international recommendation in treatment is based on the treat-to-target principle: since damage predicts subsequent damage and death, prevention of damage accrual should be a major therapeutic goal [2]. In general, this also applies to the other mentioned connective tissue diseases.

In daily practice, the physician of children with connective tissue disease acquires information on the disease activity to make treatment decisions. Besides clinical and laboratory findings, imaging can be valuable in initiating and evaluating therapy and in the awareness and prevention of complications. MRI is the modality of choice for the imaging of inflammatory musculoskeletal changes due to its multiplanar capabilities and its capacity for visualizing both soft-tissue (e.g., synovium, tendons, muscle) and osteochondral structures [3].

In juvenile idiopathic arthritis, the wrist is known for its frequency of involvement, vulnerability to erosive damage and association with poor prognosis, and therefore warrants detailed examination in children with joint complaints [4-6].

Although several large cohort studies on the musculoskeletal symptoms of children with connective tissue disease have been published [7-10], no information on pediatric MRI of the joints in these diseases is available. For adult SLE [11, 12], MCTD [13] and SSc [14], a small number of studies have been published on the MRI appearance of the wrist. Based on these studies, wrist involvement in children with connective tissue disease is expected to show abnormalities indicating inflammatory arthritis as well as the common extra-articular involvement of skin, muscles and tendons visualized by MRI as soft-tissue edema, indicating sclerosis, myositis and/or tenosynovitis [11-14].

The aim of this study is to describe the clinical characteristics and MRI findings of the wrist in a cohort of children suffering from connective tissue disease with musculoskeletal involvement.

\section{Methods}

Pediatric patients with connective tissue disease that underwent MRI of the wrist in a tertiary pediatric rheumatology center between 2008 and 2018 were retrospectively included in this case series. MRI scans were performed at an open-bore 1.0T MRI scanner (Philips Panorama HFO) or at a 3.0T MRI scanner (Philips Achieva). No sedation was used. The clinically most affected wrist was imaged before and after intravenous (IV) contrast (Gadovist, Bayer Schering Pharma, Berlin, Germany, $1.0 \mathrm{mmol}$ gadolinium/ $\mathrm{mL}$, dose $0.1 \mathrm{mmol} / \mathrm{kg}$ ). Before IV contrast, coronal/ axial T1- and T2-weighted images were acquired. After IV contrast, coronal and fat-suppressed axial sequences were obtained. Approval by the regional ethics board and informed consent by patients and/or parents was waived for this study by the Medical Ethical Committee of the Amsterdam University Medical Center, location AMC (reference number W13_166, date August 6th 2013), as all examinations were in the context of regular patient care and data were completely anonymized.

Clinical parameters (clinical history, presentation/ symptoms, laboratory values) were retrospectively acquired from the patient charts. MRI datasets were evaluated in a consensus reading session by a musculoskeletal radiologist ( $>25$ years of experience), a pediatric rheumatologist (8 years of experience) and a resident in pediatrics with 5 years of experience in pediatric musculoskeletal radiology. The MRIs of the wrist were evaluated for presence and extent of synovial inflammation and tenosynovitis by means of validated scoring systems $[15,16]$. The synovial inflammation score was based on a comprehensive evaluation of inflammatory features such as degree and extent of synovial enhancement and the presence of effusion [15]. Synovial inflammation was assessed on six locations: distal radioulnar joint, radiocarpal joint, intercarpal joint, first carpometacarpal joint, carpometacarpal joints $2-5$ and the pisotriquetral recess. A $0-2$ (none, mild or moderate/severe inflammation) scale was used for every location, leading to a maximum total score of 12 . Tenosynovitis was also scored on a $0-2$ scale, with 0 reflecting no enhancement nor thickening of the synovial sheath, 1 reflecting enhancement and mild thickening of the synovial sheath, and 2 reflecting enhancement and moderate to significant thickening of the synovial sheath [16]. Tenosynovitis was evaluated over the entire trajectory of the tendon and separately in each of the six extensor compartments, whereas the flexor tendons were scored as one group. The maximum total tenosynovitis score was 14 . Other expected ancillary findings such as bone marrow edema, bone erosions and myositis were also evaluated and documented. 
Descriptive statistics such as median, interquartile range (IQR) and frequencies were used to describe patient characteristics and clinical findings. SPSS software version 24 (IBM SPSS Statistics for Windows, Version 24.0 Armonk, NY: IBM Corp) was used for the evaluation of all data.

\section{Results}

\section{Clinical findings}

Ten patients (seven females) with connective tissue disease and MRI of the wrist were identified. This concerns approximately $13 \%$ of the total population of pediatric patients with mixed connective tissue disease in the given time period $(n=80)$. Median age at onset was 12.3 years with an IQR of $7.8-14.8$ years. Median time from disease onset to MRI was 1.4 years with an IQR of 0.4-6.6 years. At the time of MRI, median age was 14.7 years (IQR 12.7-16.6). Clinical arthritis activity as assessed on a Likert scale (0-5) was mild (score 3 ) in six of the patients $(67 \%)$; none of the patients were considered to have 'severe' clinical arthritis activity on this Likert scale. Furthermore, clinical arthritis activity as assessed on a visual analogue scale (0-100) showed a median of 19 (IQR 7-31). At the time of MRI, four patients used no medication and the other six patients used different types of medication, consisting of non-steroidal anti-inflammatory drugs, methotrexate, prednisone, Plaquenil and Cellcept. Clinical symptoms and treatment strategies during the disease course are shown in Table 1.

\section{Imaging findings}

MRI of the wrist showed extensive inflammatory findings in $7 / 10$ patients. Severe synovial inflammation was seen in $7 / 10$ patients, with total scores ranging between 7 and 12. Severe tenosynovitis as reflected by a score of 10 and higher was found in 6/10 patients. In those patients with severe tenosynovitis, flexor tendons were involved in $5 / 6$ patients. An example is given in Fig. 1.

The three patients with minimal inflammatory findings had total synovial inflammation scores of 2-4 and total tenosynovitis scores of $0-3$, respectively (which is less than $33 \%$ of the maximum scores in both items).

Myositis, reflected by high-signal intensity on the axial T2-weighted sequence as well as on the fat-suppressed T1-weighted sequence after administration of IV contrast, was found in $3 / 10$ patients (33\%). When present, myositis was always found in the volar thumb muscles (Fig. 2). Furthermore, one patient showed extensive infiltration of the subcutaneous fat, clinically correlating active sclerosis of the skin (Fig. 3).

Table 1 Characteristics of ten pediatric patients with connective tissue disease

\begin{tabular}{|c|c|c|c|c|}
\hline & Ethnicity & Auto-antibody profile & Other symptoms (besides arthritis) & Treatment if ever used \\
\hline 1 & African/Afro-Caribbean & $\begin{array}{l}\text { ANA, anti-RNP, anti-centromere, } \\
\text { anti-Scl-70, anti-SS-A, anti-ds- } \\
\text { DNA }\end{array}$ & $\begin{array}{l}\text { Myositis, Raynaud, sclerodactyly, } \\
\text { digital ulcerations, interstitial } \\
\text { pulmonary involvement, nephritis }\end{array}$ & $\begin{array}{l}\text { Hydroxychloroquine, MTX, MMF, } \\
\text { prednisolone, RTX, etanercept, } \\
\text { allogenic SCT }\end{array}$ \\
\hline 2 & African/Afro-Caribbean & $\begin{array}{l}\text { ANA, anti-RNP, anti-Sm, anti- } \\
\text { Ro52, anti-ds-DNA, RF }\end{array}$ & $\begin{array}{l}\text { Myositis, Raynaud, pleuritis, } \\
\text { pericarditis, haemolytic anemia, } \\
\text { nephritis, aphthous ulcers }\end{array}$ & $\begin{array}{l}\text { Hydroxychloroquine, MTX, MMF, } \\
\text { RTX, prednisolone, cyclophos- } \\
\text { phamide, belimumab }\end{array}$ \\
\hline 3 & Asian & $\begin{array}{l}\text { ANA, anti-RNP, anti-Sm, anti- } \\
\text { Ro52, anti-ds-DNA, RF }\end{array}$ & $\begin{array}{l}\text { Lymphadenopathy, haemolytic } \\
\text { anemia, parotitis, nephritis }\end{array}$ & $\begin{array}{l}\text { Hydroxychloroquine, MTX, pred- } \\
\text { nisolone, RTX }\end{array}$ \\
\hline 4 & Caucasian & $\begin{array}{l}\text { ANA, anti-SS-A, anti-SS-B, anti- } \\
\text { Ro52, RF }\end{array}$ & Sicca, parotitis & Hydroxychloroquine \\
\hline 5 & Caucasian & ANA, anti-RNP, anti-ds-DNA & $\begin{array}{l}\text { Autoimmune-mediated encepha- } \\
\text { lopathy, leukopenia, aphthous } \\
\text { ulcers }\end{array}$ & $\begin{array}{l}\text { Hydroxychloroquine, MTX, MMF, } \\
\text { RTX, prednisolone, IVIG, plas- } \\
\text { mapheresis }\end{array}$ \\
\hline 6 & African/Afro-Caribbean & $\begin{array}{l}\text { ANA, anti-RNP, anti-Sm, anti-ds- } \\
\text { DNA }\end{array}$ & $\begin{array}{l}\text { Leukopenia, thrombocytopenia, } \\
\text { haemolytic anemia }\end{array}$ & Hydroxychloroquine, MTX \\
\hline 7 & North African/Middle east & $\begin{array}{l}\text { ANA, anti-centromere A/anti-PM- } \\
\text { Scl100 }\end{array}$ & Dermatomyositis & MTX, IVIG, prednisolone, RTX \\
\hline 8 & Caucasian & ANA, anti-RNP & Raynaud & MTX \\
\hline 9 & Caucasian & ANA, anti-RNP & Raynaud & Hydroxychloroquine, MTX \\
\hline 10 & Caucasian & ANA & $\begin{array}{l}\text { Cutaneous LE, leukopenia, aph- } \\
\text { thous ulcers }\end{array}$ & MTX, Plaquenil \\
\hline
\end{tabular}

anti-ds-DNA anti-double stranded DNA antibodies, anti-RNP anti-RiboNuclear Protein, anti-Sm anti-Smith antibodies, $R F$ IgM rheumatoid factor, $M T X$ methotrexate, $M M F$ mycophenolate mofetil (Cellcept), $R T X$ rituximab, $I V I G$ intravenous immunoglobulins, $S C T$ stem cell transplantation 


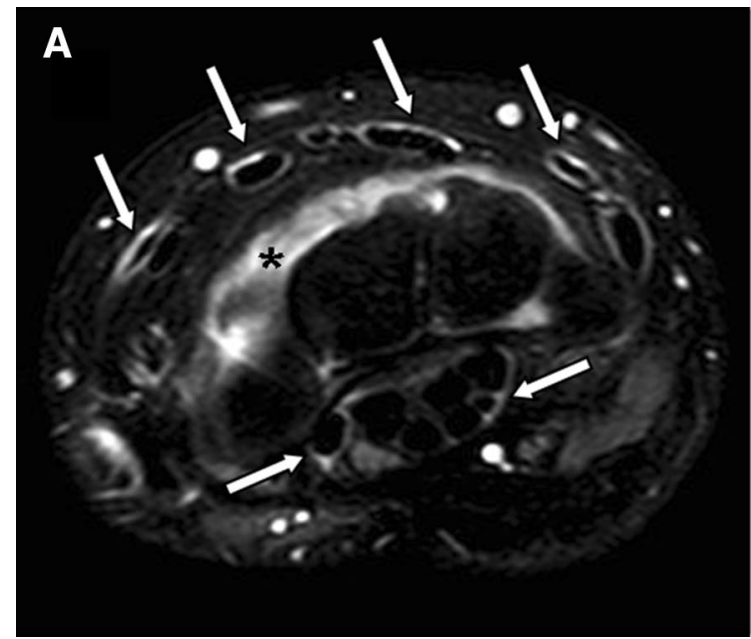

Fig. 1 Multifocal inflammatory findings in the wrist from a 17-yearold girl with mixed connective tissue disease. The midcarpal region shows synovial inflammation (asterisk) and tenosynovitis (arrows) in

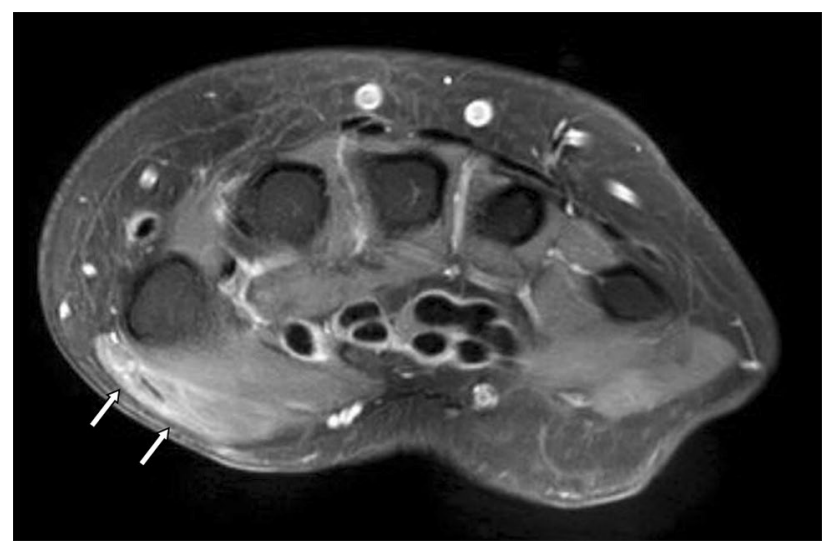

Fig. 2 Myositis in an 8-year-old boy with juvenile dermatomyositis. Axial fat-saturated T1-weighted MR image of the wrist after administration of IV contrast, visualizing high-signal intensity (enhancement) in the thenar muscles (arrows), indicative of local myositis

Osteochondral abnormalities, such as bone marrow edema and bone erosions, were found in $3 / 10$ patients (Fig. 4).

\section{Correlation clinical and imaging findings}

In all patients, clinical arthritis activity scores were relatively low [i.e., VAS $<50(0-100)$ or Likert $\leq 4(0-5)]$. On the other hand, in the majority of patients, the total MRI scores for synovitis and tenosynovitis were clearly increased [i.e., total synovitis score $>6(0-12)$ and total tenosynovitis score $>7(0-14)]$.

No correlation statistics were performed because of the small cohort.

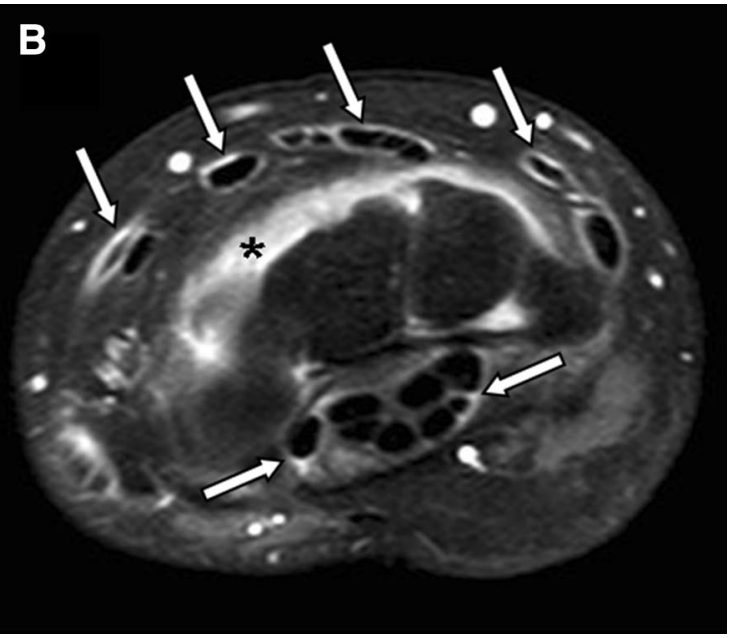

the flexor and extensor tendons on axial T2-weighted images (a) and T1-weighted images with fat saturation after IV contrast (b)

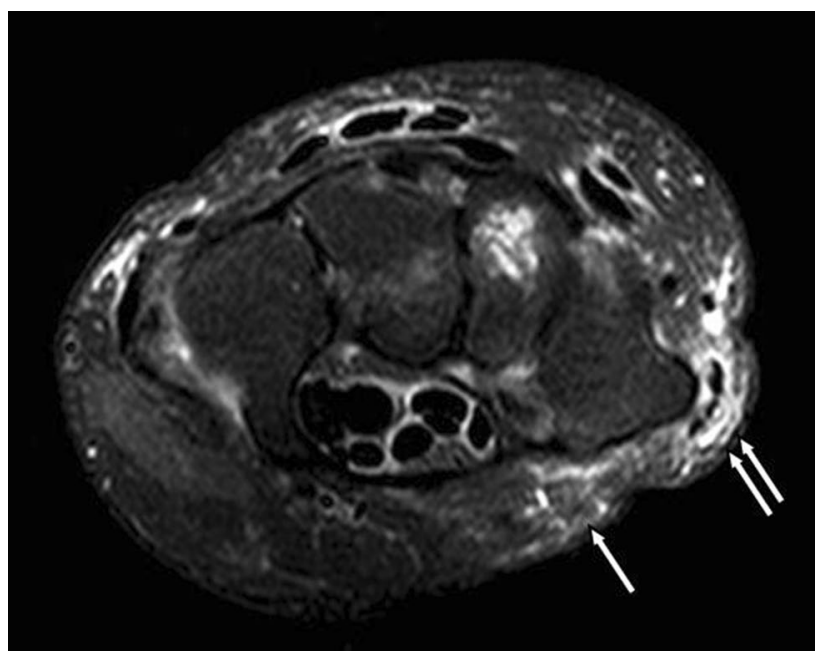

Fig. 3 Soft tissue edema in mixed connective tissue disease in a 13-year-old girl. Axial T2-weighted image (a) visualizing infiltration of the subcutaneous fat (high-signal intensity), possibly indicative of active sclerosis. Additionally, bone marrow edema in the trapezoid and tenosynovitis (enhancement on $\mathrm{T} 1$ after contrast administration, b) in both the flexor and extensor compartments are present

\section{Discussion}

To the best of our knowledge, this cohort of pediatric patients with connective tissue disease with musculoskeletal involvement is unique in describing the imaging findings of the wrist. Extensive inflammatory and osteochondral abnormalities on MRI of the wrist were observed in these patients and included involvement of flexor tendons, myositis and infiltration of subcutaneous fat indicative of 


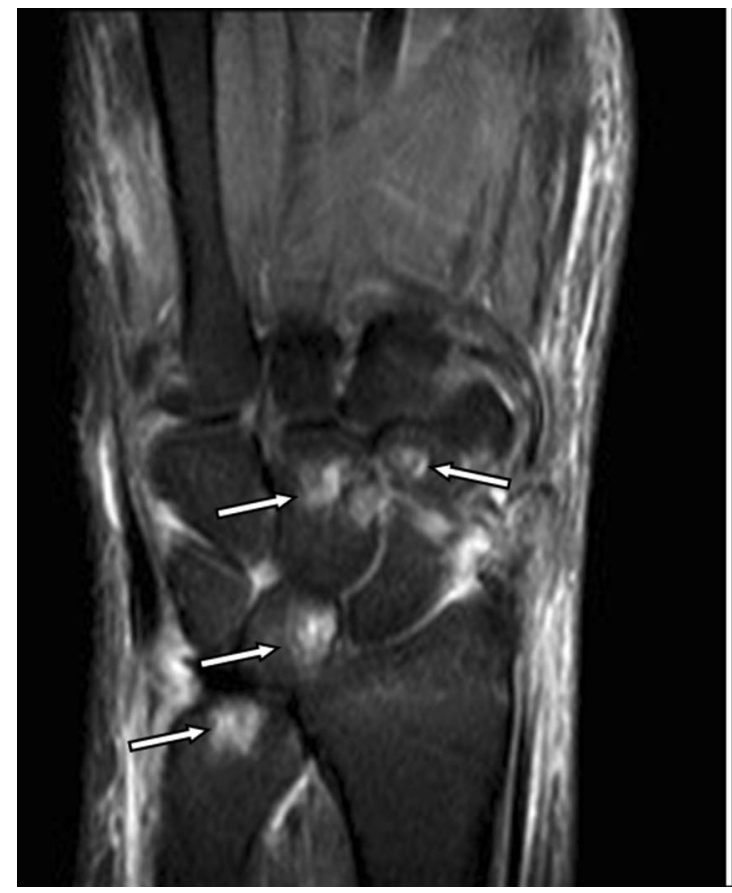

Fig. 4 Osteochondral abnormalities in a 13-year-old girl with mixed connective tissue disease. Coronal T1- (a) and T2-weighted images (b) with numerous foci of low (a) and high (b) signal intensity within

active sclerosis. Interestingly, the perceived/scored clinical arthritis activity of the wrist by the patients and their clinicians (VAS) was strikingly low, compared to the extent of the abnormalities detected with MRI. Based on these findings, the wrist deserves a thorough evaluation in daily practice as a possible vulnerable joint in children with connective tissue disease. The pattern of inflammation and damage on the MRI of the wrist as observed in patients with connective tissue disease is much more extensive compared to other arthritic diseases of childhood, such as juvenile idiopathic arthritis or reactive arthritis [4]. Although a direct comparison has not been performed, findings of pediatric connective tissue disease upon imaging of the wrist show higher synovial inflammation scores, the presence of extensive tenosynovitis and preference for the flexor tendons compared to JIA patients [4]. The findings including the extensive tenosynovitis and extracapsular inflammation have also been described upon MRI of the wrist in adults with MCTD [13]. Additionally, highsignal intensity on T2-weighted images in muscle and subcutaneous tissue, suggestive for myositis and subcutaneous edema, have been described before in a recent study on pediatric mixed connective tissue disease [17].

The presence of bone erosions and bone marrow edema is commonly observed in adults with systemic autoimmune disease $[11,12]$. However, Mosca et al. showed that bony depressions were equally frequent in the healthy control

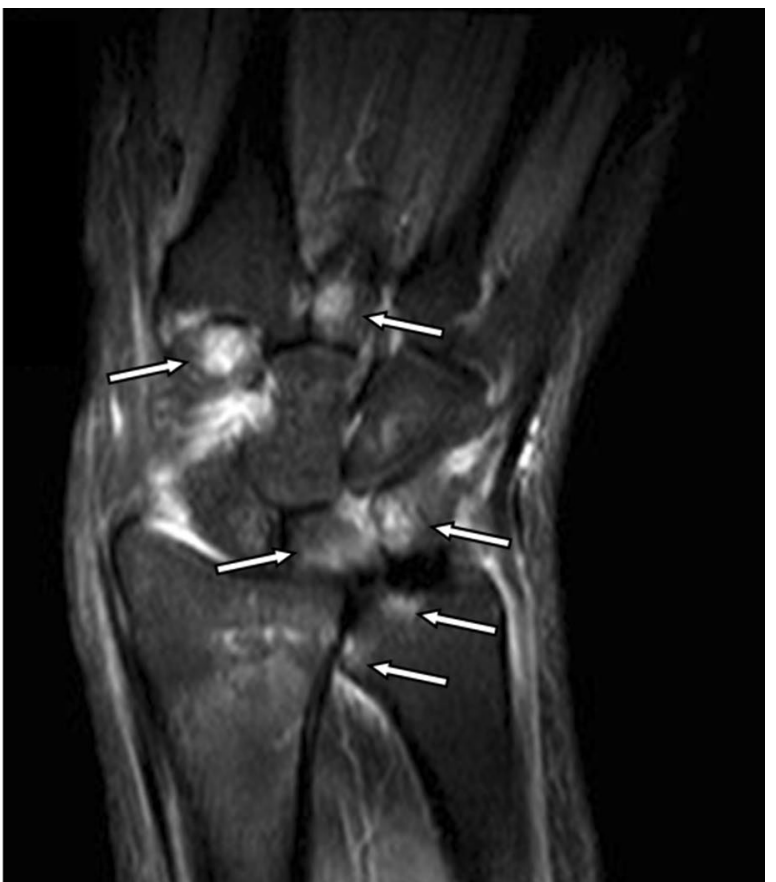

the bone marrow, in keeping with bone marrow edema and/or bone erosions indicating extensive osteochondral damage

group and hence cast doubt on the clinical significance of these findings [11]. MRI studies in healthy children have shown that bony depressions in the wrist are very commonly present and may mimic erosive pathology $[18,19]$. Nevertheless, erosions as found in our cohort can be considered 'pathologic', due to accompanying bone marrow edema and/ or synovial inflammation.

The correlation between clinical and imaging findings could not be assessed due to the small cohort size. In general though, the clinical arthritis activity was scored low compared to the high MRI inflammation scores. Based on this finding, one could cautiously state that clinical arthritis activity underestimates the inflammation as assessed with MRI in pediatric connective tissue disease-a finding that needs confirmation in larger cohorts.

A limitation of the current study was the relatively low number of patients, resulting from the fact that connective tissue disease in children is a rare entity and MRI is not routinely performed in these affected children. Furthermore, the variety of different diagnoses within the connective disease decreased to the homogeneity of the cohort. On the other hand, homogeneity was achieved with the involvement and imaging of one specific joint, i.e., the wrist.

Children suffering from connective tissue disease with musculoskeletal symptoms showed severe abnormalities on the MRI of the involved wrist. Frequent findings include extensive (teno)synovitis, osteochondral damage, myositis 
and infiltration of the subcutaneous fat. Clinical arthritis activity was strikingly low compared to the extent of the MRI abnormalities. Considering the wrist as vulnerable for erosive disease, integration of MRI in the management of patients with pediatric connective tissue disease and musculoskeletal involvement deserves consideration to better interpret disease activity and subsequently damage.

Author contributions Study concept and design: CN, DS and MM. Acquisition of data: CN, DS, KN and MM. Statistical analysis: CN. Drafting of the manuscript: $\mathrm{CN}, \mathrm{KN}$, and DS. Critical revision of the manuscript: all authors.

Funding This work was not supported by funding.

\section{Compliance with ethical standards}

Conflict of interest All authors declare that they have no conflict of interest.

Open Access This article is distributed under the terms of the Creative Commons Attribution 4.0 International License (http://creativeco mmons.org/licenses/by/4.0/), which permits unrestricted use, distribution, and reproduction in any medium, provided you give appropriate credit to the original author(s) and the source, provide a link to the Creative Commons license, and indicate if changes were made.

\section{References}

1. Berard RA, Laxer RM (2016) Pediatric mixed connective tissue disease. Curr Rheumatol Rep 18(5):28. https://doi.org/10.1007/s1192 6-016-0576-X

2. van Vollenhoven RF, Mosca M, Bertsias G, Isenberg D, Kuhn A, Lerstrom K, Aringer M, Bootsma H, Boumpas D, Bruce IN, Cervera R, Clarke A, Costedoat-Chalumeau N, Czirjak L, Derksen R, Dorner T, Gordon C, Graninger W, Houssiau F, Inanc M, Jacobsen S, Jayne D, Jedryka-Goral A, Levitsky A, Levy R, Mariette X, Morand E, Navarra S, Neumann I, Rahman A, Rovensky J, Smolen J, Vasconcelos C, Voskuyl A, Voss A, Zakharova H, Zoma A, Schneider M (2014) Treat-to-target in systemic lupus erythematosus: recommendations from an international task force. Ann Rheum Dis 73(6):958-967. https://doi.org/10.1136/annrheumdis-2013-205139

3. Cimmino MA, Bountis C, Silvestri E, Garlaschi G, Accardo S (2000) An appraisal of magnetic resonance imaging of the wrist in rheumatoid arthritis. Semin Arthritis Rheum 30(3):180-195. https ://doi.org/10.1053/sarh.2000.9204

4. Nusman CM, Hemke R, Schonenberg D, Dolman KM, Van Rossum MA, Van den Berg JM, Kuijpers TW, Maas M (2014) Distribution pattern of MRI abnormalities within the knee and wrist of juvenile idiopathic arthritis patients: signature of disease activity. AJR Am J Roentgenol 202(5):W439-W446. https://doi.org/10.2214/ AJR.13.11314

5. Al-Matar MJ, Petty RE, Tucker LB, Malleson PN, Schroeder ML, Cabral DA (2002) The early pattern of joint involvement predicts disease progression in children with oligoarticular (pauciarticular) juvenile rheumatoid arthritis. Arthritis Rheum 46(10):2708-2715. https://doi.org/10.1002/art.10544

6. Hemke R, Nusman CM, van der Heijde DM, Doria AS, Kuijpers TW, Maas M, van Rossum MA (2014) Frequency of joint involvement in juvenile idiopathic arthritis during a 5-year follow-up of newly diagnosed patients: implications for MR imaging as outcome measure. Rheumatol Int. https://doi.org/10.1007/s00296-014-3108-x

7. Sakamoto AP, Silva CA, Ferriani MP, Pereira RM, Bonfa E, SaadMagalhaes C, Okuda E, Appenzeller S, Gomes FH, Cunha AL, Salume MH, Piotto DP, Terreri MT (2016) Characterization of chronic arthritis in a multicenter study of 852 childhood-onset systemic lupus erythematosus patients. Rheumatol Int 36(12):16411648. https://doi.org/10.1007/s00296-016-3564-6

8. Hetlevik SO, Flato B, Rygg M, Nordal EB, Brunborg C, Hetland H, Lilleby V (2017) Long-term outcome in juvenile-onset mixed connective tissue disease: a nationwide Norwegian study. Ann Rheum Dis 76(1):159-165. https://doi.org/10.1136/annrheumdis-2016209522

9. Martini G, Foeldvari I, Russo R, Cuttica R, Eberhard A, Ravelli A, Lehman TJ, de Oliveira SK, Susic G, Lyskina G, Nemcova D, Sundel R, Falcini F, Girschick H, Lotito AP, Buoncompagni A, Sztajnbok F, Al-Mayouf SM, Orban I, Ferri C, Athreya BH, Woo $\mathrm{P}$, Zulian F, Juvenile Scleroderma Working Group of the Pediatric Rheumatology European S (2006) Systemic sclerosis in childhood: clinical and immunologic features of 153 patients in an international database. Arthritis Rheum 54(12):3971-3978. https://doi. org/10.1002/art.22207

10. Ramanan AV, Feldman BM (2002) Clinical features and outcomes of juvenile dermatomyositis and other childhood onset myositis syndromes. Rheum Dis Clin North Am 28(4):833-857

11. Mosca M, Tani C, Carli L, Vagnani S, Possemato N, Delle Sedie A, Cagnoni M, D’Aniello D, Riente L, Caramella D, Bombardieri $S$ (2015) The role of imaging in the evaluation of joint involvement in 102 consecutive patients with systemic lupus erythematosus. Autoimmun Rev 14(1):10-15. https://doi.org/10.1016/j.autre v.2014.08.007

12. Boutry N, Hachulla E, Flipo RM, Cortet B, Cotten A (2005) MR imaging findings in hands in early rheumatoid arthritis: comparison with those in systemic lupus erythematosus and primary Sjogren syndrome. Radiology 236(2):593-600. https://doi.org/10.1148/radio 1.2361040844

13. Cimmino MA, Iozzelli A, Garlaschi G, Silvestri E, Montecucco C (2003) Magnetic resonance imaging of the hand in mixed connective tissue disease. Ann Rheum Dis 62(4):380-381

14. Frerix M, Kroger K, Szalay G, Muller-Ladner U, Tarner IH (2016) Is osteonecrosis of the lunate bone an underestimated feature of systemic sclerosis? A case series of nine patients and review of literature. Semin Arthritis Rheum 45(4):446-454. https://doi. org/10.1016/j.semarthrit.2015.07.010

15. Damasio MB, Malattia C, de Horatio LT, Mattiuz C, Pistorio A, Bracaglia C, Barbuti D, Boavida P, Juhan KL, Ording LS, Rosendahl K, Martini A, Magnano G, Toma P (2012) MRI of the wrist in juvenile idiopathic arthritis: proposal of a paediatric synovitis score by a consensus of an international working group. Results of a multicentre reliability study. Pediatr Radiol 42(9):1047-1055. https ://doi.org/10.1007/s00247-012-2392-4

16. Lambot K, Boavida P, Damasio MB, de Tanturri HL, Desgranges M, Malattia C, Barbuti D, Bracaglia C, Muller LS, Elie C, BaderMeunier B, Quartier P, Rosendahl K, Brunelle F (2013) MRI assessment of tenosynovitis in children with juvenile idiopathic arthritis: inter- and intra-observer variability. Pediatr Radiol 43(7):796-802. https://doi.org/10.1007/s00247-012-2613-x

17. Gorkem SB, Doria AS, Tse S (2019) Imaging findings of mixed connective tissue disease in children and adolescents: a case series. Jpn J Radiol 37(5):371-379. https://doi.org/10.1007/s11604-019-00824 $-4$

18. Müller LS, Avenarius D, Damasio B, Eldevik OP, Malattia C, Lambot-Juhan K, Tanturri L, Owens CM, Rosendahl K (2011) The paediatric wrist revisited: redefining MR findings in healthy children. Ann Rheum Dis 70(4):605-610. https://doi.org/10.1136/ ard.2010.135244 
19. Avenarius DF, Ording Muller LS, Rosendahl K (2016) Erosion or normal variant? 4-year MRI follow-up of the wrists in healthy children. Pediatr Radiol 46(3):322-330. https://doi.org/10.1007/s0024 7-015-3494-6
Publisher's Note Springer Nature remains neutral with regard to jurisdictional claims in published maps and institutional affiliations. 